\title{
A Research on the Impacts of Core Employees on the Performances of SME's*
}

\author{
Kurtuluş Yılmaz Genç\# \\ Faculty of Economics and Administrative Sciences, Giresun University, Giresun, Turkey \\ Email: kurtulus.yilmaz.genc@giresun.edu.tr, kyilmazgenc@gmail.com
}

Received 13 March 2014; revised 19 April 2014; accepted 9 May 2014

Copyright (C) 2014 by author and Scientific Research Publishing Inc.

This work is licensed under the Creative Commons Attribution International License (CC BY). http://creativecommons.org/licenses/by/4.0/

(c) (i) Open Access

\section{Abstract}

This study includes a research on the impacts of core employees on the perceived performances of Small and Medium Sized Enterprises (SME's). Employees, who are working at manufacturing department or basic function, were taken as core employees in the frame of the research. This research was conducted at the Middle and Eastern Black Sea region of Turkey; at 60 SME's. The research was realised on the bases of the resource-based view of the firm; the relation between the characteristics of core employees as rareness, hardness to imitation and the perceived performances of SME's were given. This study contributes to the literature for its regional focus to the topic and for the presentation of how SME's perceive organizational performance as dimensional context. The results of the research didn't support the hypothesis which claims that there is a positive relationship between the expertises of core employees, whose superior characteristics are specific to firms and the organizational performance.

\section{Keywords}

Core Employees, Organizational Performance, SME's, Resource-Based View

\section{Introduction}

This study investigates the impacts of core employees on the perceived organizational performances of SME's. This article includes the following: first of all, the definition of core employees and their importance for businesses will be presented. Then, the hypothesis of the research will be given. Third, the methodology will be explained. The next step includes the basic findings, the results of correlation analyses for variables, and the evaluation of the results. Finally, a general conclusion will be given.

\footnotetext{
${ }^{*}$ This study was presented at the $20^{\text {th }}$ National Management and Organization Congress at May 24-26, 2012, Izmir, Turkey; and published in it's the proceedings book as an extended abstract in Turkish.

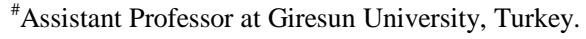




\section{Literature Review}

In recent years, one of the significant points which the literature on strategic management focused is the key role of human resources in gaining competitive advantage. According to the resource-based view of the firm, only employees who are valuable, rare, unique and properly organized can be source of competitive advantage (Barney, 1995; Barney \& Wright, 1997; Lopez-Cabrales et al., 2006). On the other hand, the competency of human resources can be imitated or substituted in the long term and firms can lose their related advantage. Therefore, as Lopez-Cabrales and colleagues (2006) stated, just valuable and inimitable employees that are properly managed can be the source of competitive advantage.

The core employees of a firm are the personnel who are working in basic function of institutions. A core employee is the worker who implements the core activity in the company and performs the organization's main activities (Lopez-Cabrales et al., 2006; Prahalad \& Hamel, 1990). In this study core employees are taken as the personnel who are working at the production department; or basic unit in marketing firms.

The core employees of a firm with special skills, abilities, and expertise are a basic resource for firms to achieve their purposes. This type of personnel with their competency or qualifications which are value, rareness, uniqueness or not easily been imitation, contribute their firms to achieve competitive advantage and sustain it. The literature on this topic supports these claims (Delaney \& Huselid, 1996; Harel \& Tzafrir, 1999; Hester, 2005; Liqun, 2004; Lopez-Cabrales et al., 2006; Takeuchi, 2003; Wright \& McMahan, 1992; Youndt et al., 1996; Wan et al., 2002; Youndt, 1998).

Barney (1991, 2001) identifies that a resource can be a source of competitive advantage if it is valuable, rare, not easily been imitated, and non-substitutable. If this view is adapted to human resources function, personnel who are valuable, rare, not easily substitutable, and well governed can create a competitive advantage for their firms (Barney \& Wright 1997; Lopez-Cabrales et al., 2006). Firm specific human capital is valuable, because it increases the efficiency of human resources; and it is not available in the labor market (Lado \& Wilson, 1994). The employees of a firm who are highly qualified, superior, and who have firm specific qualities, characteristics can provide a competitive advantage to their firms with contribution to manufacturing process.

Lado and Wilson (1994) claimed that "firms with configurations of competence-enhancing HR system attributes that are unique, causally ambiguous, and synergistic will have sustained competitive advantage over firms that have HR system configurations that are typical, causally determinate, and nonsynergistic”. This view supports the idea that, how important it is to have competent human resource to be superior to rival firms.

Carmeli and Schaubbroeck (2005) found that, valuable, unique and not easily substitutable human capital is strongly correlated with organizational performance. Similarly, Skaggs and Youndt (2004) identified that, different combinations of human capital had close links with organizational performance. In addition, Bae and Lawler (2000) achieved the result that, human capital is one of the significant sources of competitive advantage. Equally, Wright et al. (1995) noticed the link between the competency of employees and organizational outcomes. Also, Lopez-Cabrales et al. (2006) reached the result that, the firms which have the most valuable and unique core employees have the highest efficiency. Finally, Takeuchi (2003) pointed out that, the level of human resource increases the performance of work systems.

There is a linear proportion between the value, rareness, firm specific skills, abilities and specialty level of core employees in a firm and the ability of that firm to achieve a competitive advantage. This situation might increase the profitability of a firm; therefore, organization would achieve its purposes; in other words, would succeed in its activities. Consequently, at the end of this type of a process any firm might have an increased performance so would have higher profits. Thus, it can be asserted that:

H1: There is a positive relationship between the value, rareness, and non-substitutable characteristics of the core employees of a firm and its organizational performance.

If the employees of a manufacturing department are brilliant, expert, and creative; first, this function can be expected to be successful as a whole; then, this superiority will facilitate the process for an organization to succeed in its all other functions; and, finally organizational performance will increase. The competence of the core employees of a firm can easily affect customer satisfaction.

In connection with this, Lopez-Cabrales and colleagues (2006) found that core employees are positively associated with very valuable human capital. Therefore, it can be estimated that if a firm have core employees who have high levels of competence, then the outcomes of that organization will be higher. In other words, the skills and abilities of this personnel, might lead a superior efficiency. So, a second hypothesis can be proposed as: 
H2: The degree of expertise or competency of the core employees of a firm will be positively and significantly correlated with the perceived organizational performance of that firm.

The degree of value, rareness, and non-substitutable qualifications of the core employees of a firm is expected to be highly correlated with the level of creativeness of those personnel. In other words, these types of qualifications might facilitate to design and manufacture new, superior products; and to differentiate existing ones. Accordingly, it will be easier for these firms to achieve a competitive advantage by the contribution of their core employees. Equally, competency will stimulate these personnel to do their best for their firms.

Lopez-Cabrales and colleagues (2006) found that "very valuable and very unique core employees are positively associated with the technical capability for innovation". The high level of competence might raise creativity. So, as a commercial creativity, innovation is very closely associated with the unique skills and abilities of core employees. A unique scientific or educational experience or a wide experimental horizon can easily enlarge the range of products in the context of innovation. Therefore, it can be proposed that:

H3: The level of value, rareness, and non-substitutable qualifications of core employees will be significantly and positively correlated with the innovation implementations of firms.

The variety of products can be increased by the help of creativeness of the core employees of firms. Expanding the types of products should be realized with the integration of all of the functions of a firm. The research and development process can be more efficient and functional if the creativeness of basic functions can be coordinated more effectively. In other words, an efficient designing process can be implemented through a complicated collaboration among business functions, that base on creativeness.

As stated by Prahalad and Hamel (1990) companies can gain competitive advantage and sustain it with their core competencies. Equally, they can reach new markets depending on these core competencies and core skills. In relation to this, "key employees" will lead firms to manufacture new variety of products and distribute them to new markets.

Accordingly, it can be proposed that:

H4: There is a significant positive relationship between the characteristics of core employees as valuable, rare, and non-substitutable and the variety of the products of a firm.

The flexible design of an organizational structure, consolidating power, empowerment, participation or a democratic governance or an organizational climate require personnel who can succeed in such a corporation in order to be effective. In other words, an elastic design would be more effective with brilliant workers. Equally, employees with rich experiences, abilities, views, and proposes can present sophisticated outcomes in such a structure. To come up with creative ideas, it is essential to be encouraged with a functional autonomy. The core employees of a firm can present a superior performance, in terms of creating more, increasing the variety of products, or renewing existing ones in a flexible organizational structure, which reflects an open organizational climate. So it can be claimed that:

H5: The flexible design of organizational structure will be positively and significantly correlated with the variety of products.

In an organization, employees affect organizational culture and also being affected by it, with their personalities and experiences. If an organizational culture has a content or structure which encourages the skills and ability improvements of the core employees of a firm, then the level of qualifications or competency of its personnel would increase. An organizational culture can shape the channels that make it easier to achieve creative and innovative solutions to problems. Therefore, another hypothesis can be as:

H6: The unique and firm specific characteristics or qualifications of the core employees of an organization will be significantly and positively correlated with its organizational culture.

Firms should have innovative activities or implement innovation to maintain their existence, achieve competitive advantage or larger income from its competitors, in the long term. The innovation implementations of a firm are very essential to adopt itself to its business environment. Firms should focus on innovation as a strategic tool to achieve its purposes. Equally, the position of competitive advantage of firms can be based on innovation. As a result, it can be claimed that:

H7: Having a strategic vision is positively associated with the innovative activities of a firm.

The organizational culture of a firm gains new dimensions or develops itself through interaction with management activities. If an organizational culture or an organizational climate excludes autocratic implementations, rules or in other words management styles, then it will be more suitable for innovation activities. Historically, 
there is a positive relationship between management style that depends on tolerance, participation, or functional autonomy and developments in the science and techniques; which was experienced in several parts of the world. This also can be explained as the situation of no pressure on a creative power. Accordingly, it can be asserted that:

H8: There is a positive relationship between innovative activities and the organizational culture of a firm.

Figure 1 summarizes the main perspective of this study. Accordingly, core employees who are, valuable, unique, well organized and inimitable can be the source for innovation that is based on tradable creativity, which lead competitive advantage.

\section{Methodology}

This research was designed and conducted to demonstrate how important the core employees of a firm are; and to determine the relationship between the qualities or qualifications of this type of personnel and a variety of organizational management implementations. Accordingly, the hypothesis above, were determined. In the research, the characteristics of core employees were measured through two dimensions: whether employees have high level qualifications; and the condition that the employees have original, firm specific qualifications. A five degree Likert type scale was used in the research $(1=$ strongly disagree; 5 = strongly agree). The scale that measures the qualifications of employees was taken from international literature (Youndt, 1998; Takeuchi, 2003; Lopez-Cabrales et al., 2006). The scale which measures the uniqueness of the qualifications of core employees was taken from the related study of Youndt (1998). The questions to identify perceived organizational performance were gathered from the authors: Delaney and Huselid (1996); Harel and Tzafrir (1999); Hester (2005); Liqun (2004); Youndt et al. (1996). The questions of the perceived market performance were also used by Liqun (2004). In the study, the questions for "innovation”, "strategic vision”, "flexible design”, "quality management”, "organizational culture", "employee potential" and "product diversity" were taken from Lopez-Cabrales et al. (2006). The survey form was evaluated entirely; and concluded as adequate, and appropriate for Turkey. The data analysis, especially the correlation analysis presents the results of the hypothesis.

The organizational performances of firms were measured as perceived performances, in the research. Accordingly, respondents were asked to compare the position of their firms among competitors for the titles below: the quality of products, services or programs, the level of customer satisfaction, the level of employee satisfaction, and public image. Furthermore, business managers or law competent authorities were also asked to evaluate the position of their firms in their sectors. This part was the perceived organizational performance of the question form. Consequently, these are the bases for the survey.

This research was conducted in The Middle and Eastern Black Sea Region of Turkey; as in the Organized Industrial Areas of Samsun, Ordu, Giresun, Trabzon and Fatsa; at the March and April 2012. The sample includes 60 Small and Middle Sized Enterprise (SME)'s from various sectors. Complex questions were used to identify the practices of firms. The field research was carried out as one-to-one conversations. The statistical analyses were realized by using IBM SPSS Statistics 19 . The hypothesis was analyzed by the result of correlation analysis.

The content of the sample were as follows: nineteen (32\%) of the firms were form manufacturing sector which operate in different sub sectors, five (8\%) of them were chemistry firms, seven (12\%) of them were operating in textile industry, fifteen (25\%) of them were food sector companies (approximate rates). In addition there were five (8\%) construction, six (10\%) machine manufacturing and finally three (5\%) iron-steel firms. They were founded between the years of 1940 and 2011 (71). 7 of them were established before the year 2000. The area and the number of establishments are Samsun (28; 46\%), Ordu (14; 23\%), Trabzon (7; 11\%), Giresun (6; $10 \%)$, and finally Fatsa (5; 8\%). They were all Turkish private sector firms. The numbers of employees were changing between 25 and 240 .

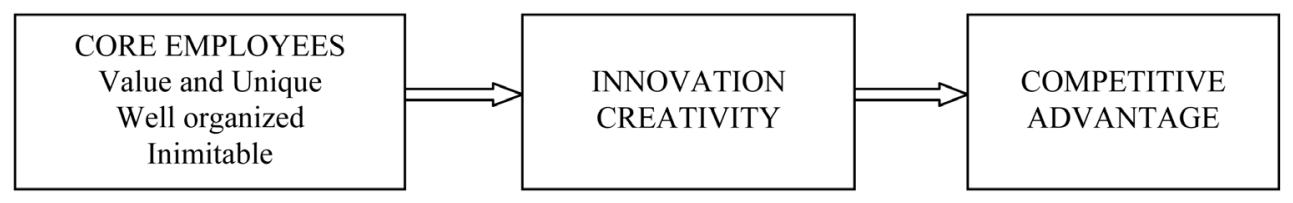

Figure 1. A model for competitive advantage which depends on the qualities of core employees. 


\section{Results}

As it can be seen at Table 1; the correlation analysis reveals the followings:

There is no statistically significant relationship between the value, uniqueness, and non-substitutability of core employees and the organizational performance of firms. In other words, the hypothesis 1 (H1) was not supported. Similarly, the second hypothesis was also rejected. In other words, there is no relationship between the levels of the expertise and organizational performance, according to the data analysis. The hypothesis 3 (H3) was supported; as the level of value, rareness, and non-substitutable qualifications of core employees are significantly and positively correlated (.398) with the innovation implementations of firms; at .01 levels. There is no significant and positive relationship between the characteristics of core employees as valuable, rare, and non-substitutable and the variety of the products of a firm. Accordingly, the hypothesis $4(\mathrm{H} 4)$ was rejected. The projection that, the flexible design of organizational structure will be positively and significantly correlated with the variety of products (H5) was not supported by the results of the data analysis. It was also revealed that, the unique and firm specific characteristics or qualifications of the core employees of an organization are not significantly and positively correlated with its organizational culture. Therefore, the hypothesis 6 (H6) is also rejected. The results of the data analysis support the seventh hypothesis (H7), which claims that, having a strategic vision is positively associated with the innovative activities of a firm. Although there is not a strong link (.350) between these two variables, the significant relationship (.01 levels) demonstrates how important it is the leadership or top governance influence on innovation activities. On the other hand, as it was projected by the hypothesis 8 (H8), innovative activities and the organizational culture of a firm were significantly and positively related; the results did not support this. Accordingly, H8 was rejected.

The correlation analysis results showed that, there is significantly and positively relationship between the variety of products and strategic vision $(.311 ; .05)$; again the variety of products and organizational culture (.465; .01).

The results related to the variables also revealed that; the qualifications of the employees, in terms of skills and expertise, who are working at the basic functions of firms (3.966); uniqueness of these skills and expertise (3.933), having a strategic vision (4.383), level of importance that firms give to service innovations or creativity (3.466), flexibility of organizational structure (4.016), dominance of organizational culture (4.766), product diversity (3.800), and perceived organizational performance (4.400) have relatively high means. This finding can be related to the level of skills and abilities or the competency of employees of these firms. Accordingly, it can be concluded that the higher the competency level of core personnel of firms, the higher the perceived organizational performance is. At the same time, the $81.7 \%$ of firms were founded before 2006, and this demonstrates that these organizations are strong firms that were adapted their business environment.

\section{Discussion}

In the Central and Eastern Black Sea Region of Turkey, striking characteristics and many problems were observed. Leadership is accepted as essential for an effective management. Enterprises try to satisfy customers

\begin{tabular}{|c|c|c|c|c|c|c|c|c|c|c|c|}
\hline & Variable & Mean & Std. Dev. & 1 & 2 & 3 & 4 & 5 & 6 & 7 & 8 \\
\hline 1. & Expertise & 3.966 & .919 & 1 & - & - & - & - & - & - & - \\
\hline 2. & Uniqueness & 3.933 & 1.313 & $.475^{* *}$ & 1 & - & - & - & - & - & - \\
\hline 3. & Vision & 4.383 & .940 & .250 & $.392^{* *}$ & 1 & - & - & - & - & - \\
\hline 4. & Innovation & 3.466 & 1.661 & $.398^{* *}$ & $.457^{* *}$ & $.350^{* *}$ & 1 & - & - & - & - \\
\hline 5. & Flexible Design & 4.016 & 1.157 & .128 & .068 & .103 & .031 & 1 & - & - & - \\
\hline 6. & Org. Culture & 4.766 & .532 & -.224 & .002 & .012 & .049 & .171 & 1 & - & - \\
\hline 7. & Product Variety & 3.800 & 1.654 & -.004 & .197 & $.311^{*}$ & .189 & -.099 & $.465^{* *}$ & 1 & - \\
\hline 8. & Performance & 4.400 & .741 & .144 & .167 & .068 & .094 & .051 & .112 & .66 & 1 \\
\hline
\end{tabular}

${ }^{* *}$ Correlation is significant at .01 levels. ${ }^{*}$ Correlation is significant at .05 levels. $\mathrm{N}=60$. 
with high quality in their products. Total Quality Management (TQM), is a popular management style or approach implemented in the region. Equally, international standards are aimed to be achieved in quality management. Moreover, quality is perceived as a culture and seen as the first instrument to be competitive. Therefore, European standards are taken as a target by firms. Every firm focuses on adaptation to system, or market.

Basic characteristics that are demanded from employees are honest behaviour, trustable work, success in teamwork, and punctuality. In other words, they should be straightforward and sincere. In addition, regularity and cleanness is essential; and personnel should have a regular family life. It was expressed that, if an employee does not adapt herself/himself to system, then she/he will be put out of it. Similarly, if an employee doesn't know the details of job, then she/he has to learn. If does not, again she/he will be left out of system. Nobody is allowed to misuse anything. Firms implement a two months trial period which depend on the law, and decide their permanent personnel. Business organizations in the region which are in the sample have friendly atmosphere which encourages employee participation.

As a problem, wages are different. Equally, the absence of qualified employees is another problem. The head of each department selects personnel for that unit. Openness to participation is one of the most widely mentioned styles in the region in corporate, business, functional or operational levels. Furthermore, there is an understanding that each personnel represents firm. Therefore, any employee who misuses system is not tolerated. The recruitment of personnel is done in two ways. First approach and practice is the employment of inexperienced but trustable personnel and training them on the work, and improving their skills and abilities towards the standards of enterprise. It was expressed by some firms that, if an enterprise employ an experienced person, she/he will cause a problem. Even the managers of some innovator firms which have competitive advantage state this opinion. Accordingly, for them, candidates should be superior and creative. On the other hand, any personnel should be more than the age of 16 according to law. The second implementation is the recruitment of experienced personnel, but an average education level is demanded; and this level is the degree of technical high school. At the same time, enterprises are more selective in recruiting top/upper management. Finally it was argued that, new personnel should remove the related weaknesses of a firm, in other words should complete it.

Management activities focus on improving the feeling of belonging. Informal behaviours like to gossip is not tolerated. The management of many firms are congratulating special days of their personnel as $8^{\text {th }}$ March and $1^{\text {st }}$ May to support employee satisfaction, and belonging. They are trying to honour all of their personnel. Firms are seeking for continuous development, so educating their personnel continuously; and monetary rewards are used for outcome. Equally, Human Resource Management (HRM) activities aim to present mentally healthy people to society. In addition, there are presentations about developments in organization. In the same way, organizations are trying to achieve efficiency with the rotation of personnel; and also brainstorming is used to support this process.

The absence of continuity and discipline make employees inefficient, so many firms focus to improve these two concepts. Equally, organizations demand employees who obey rules and regulations. In relation with this, an effective reward system is used by many organizations. However, it was also argued that, reward system may cause an opposite performance. Similarly, wages are connected with performance; but again, it was claimed that, wage according to performance can create chaos. In other words, pay according to performance sometimes causes reaction from employees; therefore it was given up by many firms. On the other hand, it was also stated that, there can't be equal wages; and, it should be determined according to responsibility.

In particular an effective reporting system was expressed to be essential. Furthermore, outsourcing in food and cleaning are being implemented. Also, many enterprises give importance to behave in the frame of ethics. In relation to this, they are rejecting any type of discrimination. So, organizations are trying to set up a home or family climate.

Consequently, these are the managerial instruments of firms which are in the sample of this research. In particular, some firms use them in a unique way, and gain sustained competitive advantage. The line of management makes core employees more creative; and this leads a firm to a superior level.

\section{Conclusion}

This study is based on a research that was conducted in the Middle and Eastern Black Sea region of Turkey. The basic aim of the research is to show the importance of core employees to organizational performance. The results of the data analysis revealed that, there is a statistically significant relationship between the value, uniqueness, and non-substitutability of core employees and the innovation activities of firms. Also, there is a positively 
significant relationship between innovation activities and having a strategic vision. The core employees of an organization, who have firm specific skills, abilities and expertise, can be expected to have direct influence on the innovation activities of a firm; and finally, this might facilitate achieving the aim of competitive advantage. It is also important that, these types of findings have been achieved in the Middle and Eastern Black Sea region of Turkey. A significant proportion of firms of this region of Turkey are aimed to be active both in local and international markets. Accordingly, to achieve competitive advantage in local markets, and to sustain at least competitiveness in international markets, it is necessary to employ manufacturing unit employees who are innovation oriented, creative; and also have firm specific qualifications. The results of the data analysis support this.

There is another important finding that, innovation activities of firms have a statistically significant relationship with having a strategic vision. This indicates that, firms are in the right way in terms of strategic orientation. A right business strategy facilitates the process to achieve profitability, a sustainable competitive advantage, and finally to become larger. Today, a right, well designed strategy should include a significant innovation focus to respond its stakeholders' demands in changing, populated, so complex strategic environment. The sample of the research includes dynamic companies who generally are aiming to be among the best firms of their sector. This finding reflects this situation.

The results of the field research analysis indicated that, there is no statistically significant relation between the expertise or competency of core employees and organizational performance. Equally, findings do not support the hypothesis which asserts that, there should be a statistically significant relationship between the value, uniqueness, and non-substitutability of core employees and the organizational performance of firms. The characteristics mentioned above can be evaluated in the frame of the resource-based view of a firm. However, this study could not achieve any evidence connected with this view, related to that basic hypothesis. It generally can be expected that, core employees who have high level expertise, and creativeness, who develops new ideas, knowledge and products, would increase organizational performance. But, the findings of this research are not in this direction. The reasons behind this situation might be the largeness of the sample; or the superiority of the mean of perceived organizational performance than the mean of employee characteristics.

The high means of the following variables, including the expertise of core employees as a team, their firm specific characteristics, innovation, strategic vision, product diversity, and finally organizational performance demonstrates how dynamic and successful firms all they are. In addition, $71.7 \%$ of these firms founded before the year of 2000; and this also reflects and supports the circumstance mentioned above. In other words, these organizations have adapted to their business environment, or can respond the requirements of competition. Accordingly, these firms all can be defined as strong. Although the correlation analysis did not support the related hypothesis, it is obvious that, this situation basically depends on the roles of the core employees working in manufacturing departments.

The relation between the value, uniqueness, and non-substitutability of core employees and organizational performance should be searched in different regions, in different sectors among diverse size enterprises or any organizations. It is obvious that, future research which will focus on the relation between the value, uniqueness, and non-substitutability of core employees and organizational performance way reveal how critical the core employees for organizations are.

\section{References}

Bae, J., \& Lawler, J. J. (2000). Organizational and HRM Strategies in Korea: Impact on Firm Performance in an Emerging Economy. Academy of Management Journal, 43, 502-517. http://dx.doi.org/10.2307/1556407

Barney, J. B. (1991). Firm Resources and Sustained Competitive Advantage. Journal of Management, 17, 99-120. http://dx.doi.org/10.1177/014920639101700108

Barney, J. B. (1995). Looking inside for Competitive Advantage. Academy of Management Executive, 9, 49-61.

Barney, J. B., \& Wright, P. M. (1997). On Becoming a Strategic Partner: The Role of Human Resources in Gaining Competitive Advantage. Human Resource Management, 37, 31-46. http://dx.doi.org/10.1002/(SICI)1099-050X(199821)37:1<31::AID-HRM4>3.0.CO;2-W

Barney, J. B. (2001). Is Resource-Based View a Useful Perspective for Strategic Management Research? Yes. Academy of Management Review, 26, 41-55.

Carmeli, A., \& Schaubroeck, J. (2005). How Leveraging Human Resource Capital with Its Competitive Distinctiveness Enhances The Performance of Commercial and Public Organizations. Human Resource Management, 44, 391-412. http://dx.doi.org/10.1002/hrm.20081 
Delaney, J. T., \& Huselid, M. A. (1996). The Impact of Human Resource Management Practices on Perceptions of Organizational Performance. Academy of Management Journal, 39, 949-969. http://dx.doi.org/10.2307/256718

Harel, G. H., \& Tzafrir, S. (1999). The Effect of Human Resource Management Practices on the Perceptions of Organizational and Market Performance of the Firm. Human Resource Management, 38, 185-200. http://dx.doi.org/10.1002/(SICI)1099-050X(199923)38:3<185::AID-HRM2>3.0.CO;2-Y

Hester, L. J. (2005). The Impact of Strategic Human Resource Management on Organizational Performance: A Perspective of the Resource-Based View of the Firm. Ph.D. Thesis, Fort Lauderdale, FL: Nova South-Eastern University.

Lado, A. A., \& Wilson, M. C. (1994). Human Resource Systems and Sustained Competitive Advantage: A CompetencyBased Perspective. Academy of Management Review, 19, 699-727.

Liqun, W. (2004). An Examination of Strategic Human Resource Management and Firm Performance in Chine. Ph.D. Thesis, Honk Kong: Chinese University of Hong Kong.

Lopez-Cabrales, A., Valle, R., \& Herrero, I. (2006). The Contribution of Core Employees to Organizational Capabilities and Efficiency. Human Resource Management, 45, 81-109. http://dx.doi.org/10.1002/hrm.20094

Prahalad, C. K., \& Hamel, G. (1990). The Core Competence of the Corporation. Harvard Business Review, May-June.

Skaggs, B. C., \& Youndt, M. (2004). Strategic Positioning, Human Capital, and Performance in Service Organizations: A Customer Interaction Approach. Strategic Management Journal, 25, 85-99. http://dx.doi.org/10.1002/smj.365

Takeuchi, R. (2003). How Do We Get From There to Here? Understanding the Black Box in Strategic HRM Research Resource-Based and Social Exchange Perspectives. Ph.D. Thesis, College Park, MD: The University of Maryland.

Wan, O., Ong, C. H., \& Kok, V. (2002). Strategic Human Resource Management and Organizational Performance in Singapore. Compensation Benefits, 34, 33-42. http://dx.doi.org/10.1177/0886368702034004006

Wright, P. M., \& McMahan, G. C. (1992). Theoretical Perspectives of Strategic Human Resource Management. Journal of Management, 18, 295-320. http://dx.doi.org/10.1177/014920639201800205

Wright, P. M., Smart, D. L., \& McMahan, G. C. (1995). Matches between Human Resources and Strategy among NCAA Basketball Teams. Academy of Management Journal, 38, 1052-1074. http://dx.doi.org/10.2307/256620

Youndt, M. A., Snell, S. A., Dean Jr., J. W., \& Lepak, D. P. (1996). Human Resource Management, Manufacturing Strategy, and Firm Performance. Academy of Management Journal, 39, 836-866. http://dx.doi.org/10.2307/256714

Youndt, M. A. (1998). Human Resource Management Systems, Intellectual Capital and Organizational Performance. Ph.D. Thesis, University Park, PA: The Pennsylvania State University. 
Scientific Research Publishing (SCIRP) is one of the largest Open Access journal publishers. It is currently publishing more than 200 open access, online, peer-reviewed journals covering a wide range of academic disciplines. SCIRP serves the worldwide academic communities and contributes to the progress and application of science with its publication.

Other selected journals from SCIRP are listed as below. Submit your manuscript to us via either submit@scirp.org or Online Submission Portal.
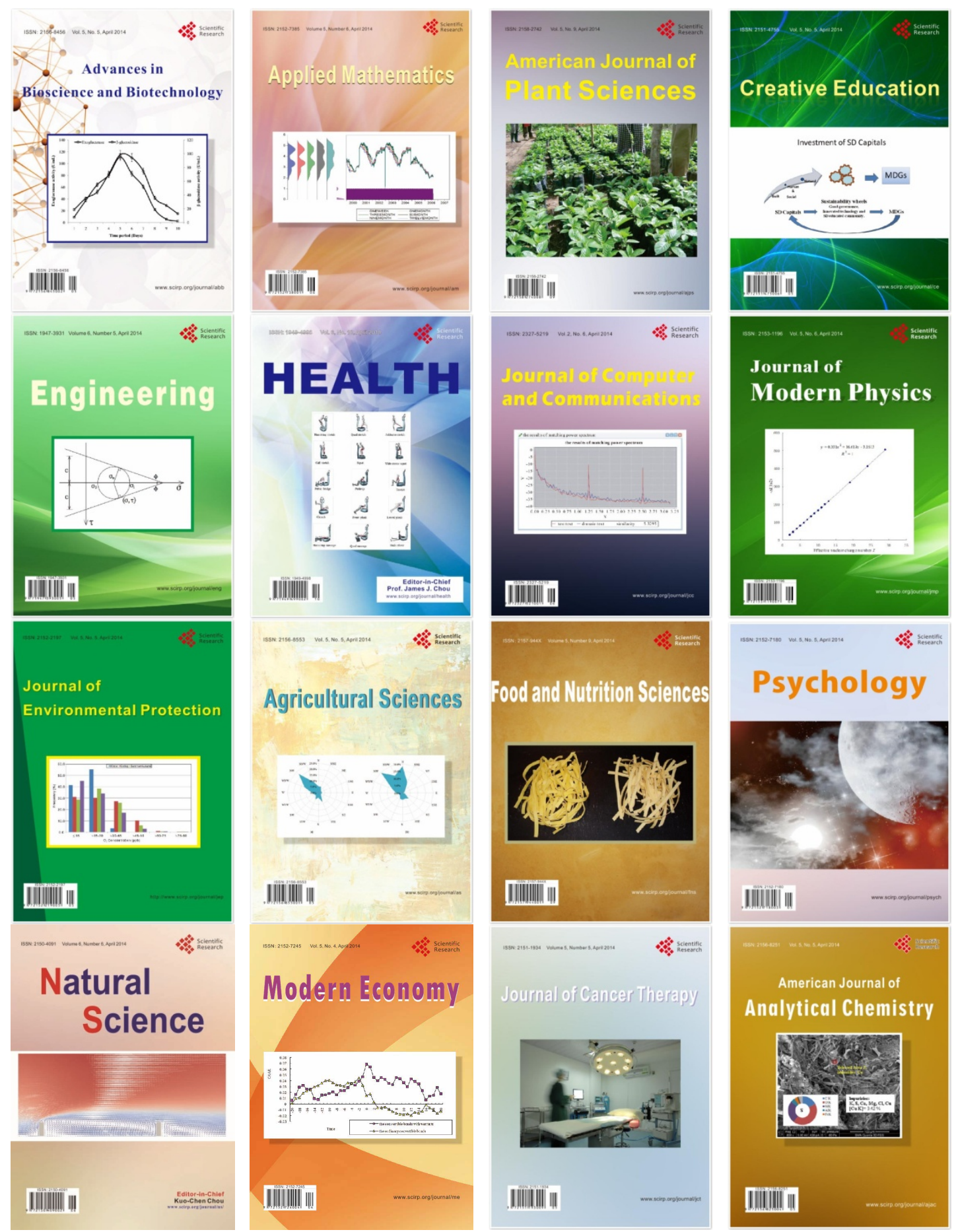